Ephéméride de la comète $1904 \mathrm{~d}$

calculée par M. Giacobini pour $\mathbf{I}^{\mathrm{h}}$ temps moyen de Paris.

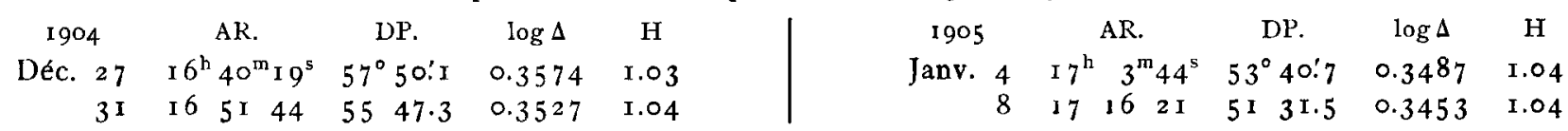

Nice, le 24 décembre 1904 .

Le Directeur de l'observatoire: Bassot.

\title{
Elemente und Ephemeride des Kometen 1904 d.
}

Aus den Beobachtungen Dez. I 7 (Nizza), Dez. 2 I (Mittel aus zwei photographischen Aufnahmen von Prof. Wolf in Königstuhl) und Dez. 26 (photogr. Aufnahme, Königstuhl) habe ich mit Berücksichtigung von Parallaxe und Aberration die folgenden Elemente abgeleitet. Der mittlere Ort wird innerhalb der Genauigkeit der fünfstelligen Rechnung dargestellt.

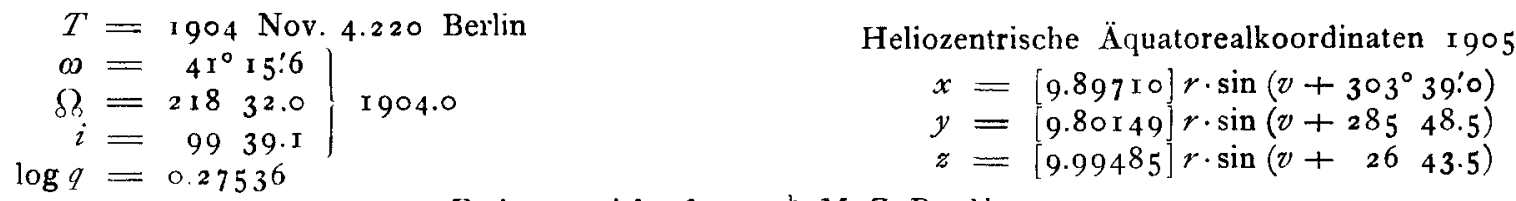

Ephemeride für I $2^{\text {h }}$ M. Z. Berlin.

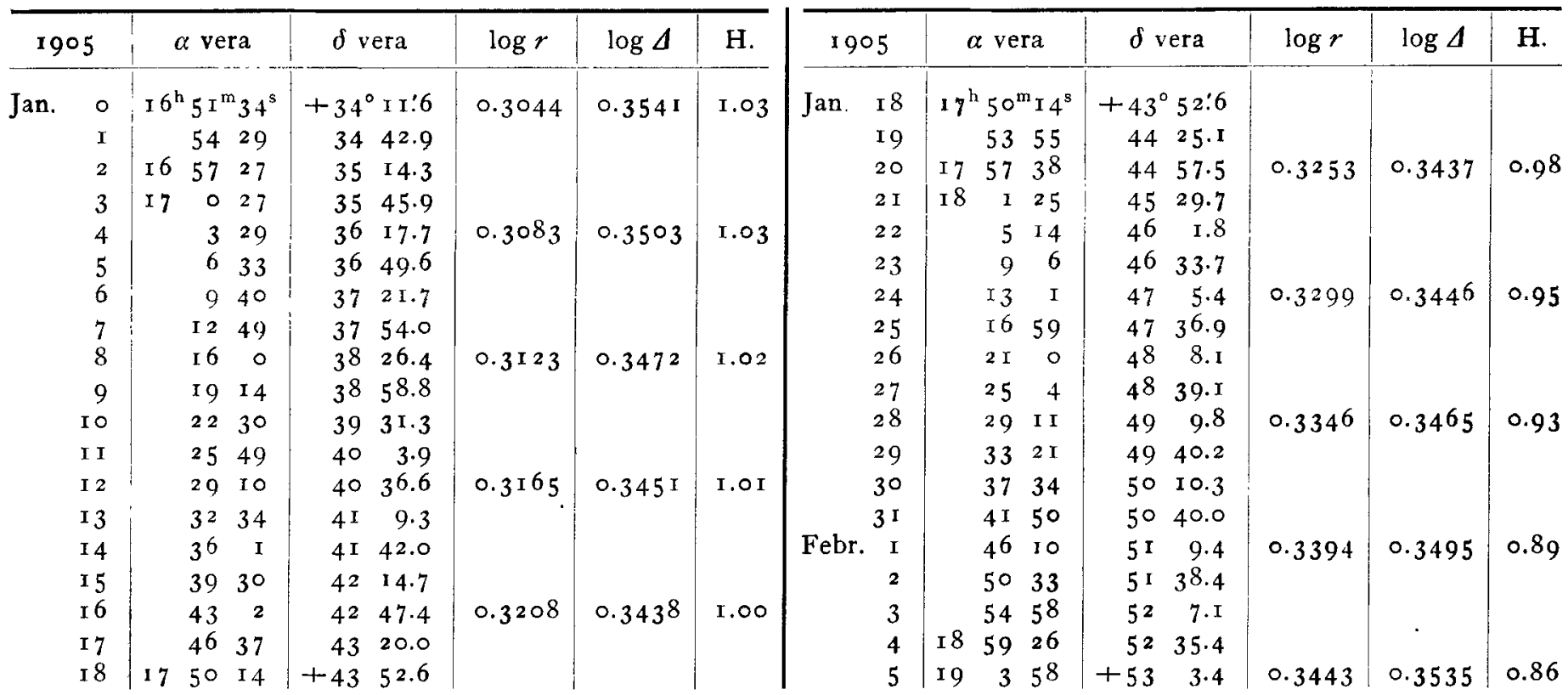

Einheit der Helligkeit: 1904 Dez. I 7 .

Kiel, Bureau der Astron. Nachrichten, I 904 Jez. 29.

Martin Ebell.

Beobachtungen von kleinen Planeten auf der k. k. Sternwarte in Wien.

\begin{tabular}{|c|c|c|c|c|c|c|c|c|c|c|c|c|c|c|}
\hline $\begin{array}{l}\text { Planet } \\
1904 \text { OW }\end{array}$ & $\begin{array}{l}190 \\
\text { Dez. }\end{array}$ & 4 & & Z.W & & $\begin{array}{l}\mathrm{Gr} . \\
\mathbf{I} \mathbf{I}_{\mathbf{m}}^{\mathbf{m}}\end{array}$ & 1 & & ${ }_{2}^{\mathrm{s}} 16$ & $\begin{array}{l}\log p . \Delta \\
8.578\end{array}$ & - & $\begin{array}{l}8 \text { apl } \\
{ }^{\circ} 3 \mathrm{I}\end{array}$ & 22 ". & $\begin{array}{c}\log p . \Delta \\
0.8 \text { I } 9\end{array}$ \\
\hline $1904 \mathrm{PC}$ & , & 28 & Io & 7 & 55 & 13.0 & 2 & 2 I & 13.72 & $9 \cdot 340$ & +9 & 30 & 34.4 & $0.75 \mathrm{I}$ \\
\hline I $904 \mathrm{PH}$ & " & 27 & 9 & 25 & 32 & 13.0 & 3 & 58 & 16.30 & $8.243 n$ & +26 & I 4 & 19.0 & $0.5 x_{5}$ \\
\hline $1904 \mathrm{PK}$ & " & 27 & 8 & 59 & I 7 & I 2.0 & 4 & 34 & 23.76 & $9.126_{n}$ & +25 & $4 \mathrm{I}$ & 5.9 & 0.540 \\
\hline $1904 \mathrm{PL}$ & » & I 6 & I 4 & 8 & 32 & - & 4 & 46 & 35.43 & 9.493 & +26 & 4 & 14.5 & 0.609 \\
\hline $1904 \mathrm{PM}$ & " & I 6 & I 4 & 34 & 54 & - & 5 & 3 & 29.50 & 9.502 & +23 & 28 & 37.5 & 0.647 \\
\hline
\end{tabular}

Eine Beobachtung von PH, Dez. I6, kann vorläufig noch nicht mitgeteilt werden, da der Vergleichstern nicht bestimmt ist.

Wien, 1904 Dez. 29.

F. Palisa.

Pianeta 1904 NY. Il pianetino r904 NY, scoperto il 20 Aprile a Königstuhl dal prof. Max Wolf, dietro mia preghiera e per sua estrema cortesia, fu dal predetto professore denominato Herculina. E. Millosevich. 